\title{
Evaluation of Inoculation Methods to Determine Resistance Reactions of Wheat to Fusarium graminearum
}

\author{
Jessica S. Engle, Graduate Research Associate, and Laurence V. Madden and Patrick E. Lipps, Professors, De- \\ partment of Plant Pathology, OARDC, The Ohio State University, Wooster 44691
}

\begin{abstract}
Engle, J. S., Madden, L. V., and Lipps, P. E. 2003. Evaluation of inoculation methods to determine resistance reactions of wheat to Fusarium graminearum. Plant Dis. 87:1530-1535.

Reliable greenhouse assays are needed to differentiate types of resistance in wheat to Fusarium graminearum. Genotypes with known field reactions were evaluated for resistance type using four greenhouse inoculation techniques. Percentage of spikelets with symptoms per spike (severity) and percentage of inoculated spikelets per spike developing symptoms were assessed 7 , 10, and 14 days after inoculation (DAI). Genotypes were evaluated using disease assessments 14 DAI and area under the disease progress curve (AUDPC). Significant genotype-inoculation technique interactions for disease assessments indicated that genotypes responded differently to greenhouse inoculation techniques. The central floret injection technique used to assess resistance to spread within the spike (type II resistance) did not indicate a resistant response in genotypes with low field disease severity (putative type II). Atomizing macroconidia onto spikes, used to assess resistance to primary infection (type I resistance), indicated a resistant response in one of five genotypes with low field disease incidence (percentage of spikes with symptomatic spikelets) (putative type I). The inoculation techniques in the greenhouse were unable to differentiate between different types of partial resistance. Results indicated disparity in the ability of greenhouse inoculation methods to identify genotypes with partial resistance as observed in the field. It was concluded that atomizing conidia onto the spikes and assessing disease severity did not differentiate between resistance types. Additionally, a one-time assessment 14 DAI was determined to be as informative as multiple assessments and calculating the AUDPC.
\end{abstract}

Additional keywords: Gibberella zeae, Triticum aestivum

Fusarium head blight of wheat (Triticum aestivum L.), caused by Fusarium graminearum Schwabe (teleomorph of Gibberella zeae (Schwein.) Petch), has become a severe problem in the United States as a result of increased implementation of reduced tillage grain production, especially in areas where wheat follows corn (Zeae mays L.) $(3,9,17)$. Infection of the floret causes sterility, poor seed fill, and poor seed quality, resulting in yield loss $(2-4,27,33)$. This fungus also produces a mycotoxin, deoxynivalenol (DON), that adversely affects livestock and humans when contaminated grain is ingested $(2,3,12,27,33)$.

Some level of control of Fusarium head blight has been achieved by applying fun-

Corresponding author: P. E. Lipps

E-mail: lipps.1@osu.edu

Salaries and research support were provided by State and Federal Funds appropriated to the Ohio Agricultural Research and Development Center, the Ohio State University. Partial funding was obtained from the U. S. Wheat and Barley Scab Initiative.

Accepted for publication 19 August 2003.

Publication no. D-2003-1009-01R

(C) 2003 The American Phytopathological Society gicides during anthesis; however, in many locations, fungicides have not been cost effective $(2,3,11,19,22)$. Recommended cultural practices include burying crop residues by mold-board plowing, crop rotation with 2 years of a non-host crop between wheat, and planting moderately resistant cultivars of wheat $(2,3,12,19,21$, $22,26,27)$. Currently, there is no winter wheat cultivar with complete resistance to Fusarium head blight; only cultivars with moderate levels of resistance have been released $(2,3,11,19,27,33,35)$.

Resistance in wheat to $F$. graminearum has been characterized using various tests that appear to differentiate among types of resistance $(3,14,31)$. Although several types of resistance have been described (20), standard greenhouse screening methods have been developed to evaluate only two types. Genotypes generally are ranked based on the percentage of spikelets with symptoms per spike and are compared with genotypes with known reactions.

Resistance to primary infection, type I resistance (31), is evaluated by spraying spikes with a macroconidial suspension to the point of runoff using a hand atomizer $(18,26,31)$. This procedure effectively establishes infection without wounding the spike and ensures that all tissues of the spike receive inoculum. A low percentage of spikelets affected per spike indicates some degree of resistance.

Spread of the pathogen within the spike, type II resistance (31), is evaluated by injecting a macroconidial suspension into a single central floret of the spike using a hypodermic syringe or a micropipette $(3,18)$. A low percentage of affected spikelets per spike indicates that the genotype limits colonization of the spike by the fungus. This test has been used to separate moderately resistant from the more susceptible genotypes (4).

Assessing resistance in the field has been considered more reliable than testing in the greenhouse because of environmental effects on resistance reactions that may not be reproduced in the greenhouse (13). It has been suggested that genotypes be tested over multiple environments to adequately evaluate the resistance level in the field $(7,26)$. Results from the Northern and Southern Uniform Scab Nurseries planted at multiple locations over 2 years indicate that the correlation between field severity and greenhouse severity ranged from $r=0.64$ to $0.76(16,23,24,32)$. This moderate correlation suggests that the greenhouse inoculation procedures are valuable for identifying resistant germ plasm, but other factors may contribute to the resistance response in the field.

Field evaluations are conducted only once per year for wheat; therefore, breeding programs frequently rely on greenhouse procedures to achieve rapid progress toward the development of resistant germ plasm. Breeding programs attempt to develop greenhouse methods that mimic natural infection processes and specifically detect types of resistances most effective in the field. It is essential that results of greenhouse tests correlate well with resistance reactions of genotypes grown under epidemic conditions in the field in order to meet the goal of releasing stable, highly resistant cultivars to growers.

The primary objective of this study was to evaluate the ability of greenhouse inoculation techniques to identify genotypes with varying levels of resistance to $F$ graminearum previously identified in the field. The second objective was to determine if different greenhouse inoculation techniques could be used to identify different types of resistance. A third objective was to determine if genotype differences could be detected using a one-time assessment or if the resistance response could be 
assessed more adequately using multiple assessments and calculating area under the disease progress curve (AUDPC).

\section{MATERIALS AND METHODS}

Seven genotypes were selected from the 1999 uniform winter wheat Fusarium head blight screening nursery (6) based on variation in reaction to Fusarium head blight (Table 1). Mean disease incidence (percentage of spikes with at least one symptomatic spikelet) and data from six field locations in the United States and one field location in Ontario, Canada of the 1999 Fusarium head blight screening nursery indicated that cvs. Ernie and IL94-1909 were more resistant than Pioneer brand 2545 (susceptible), whereas Goldfield, OH552, OH609, and IL95-4162 had intermediate reactions. Goldfield, OH609, and IL95-4162 had significantly lower disease incidence than 2545, but their disease severity ratings (percentage of symptomatic spikelets per spike) were not significantly different from 2545. Conversely, disease incidence for $\mathrm{OH} 552$ was not significantly different from 2545 , but its mean severity was significantly lower than 2545 and did not differ from Ernie or IL94-1909. All genotypes had significantly lower DON levels in harvested grain than 2545.

Seed of all genotypes, obtained from original sources $(6,10)$, were germinated and vernalized for approximately 65 days in a $3.5^{\circ} \mathrm{C}$ growth chamber with an 8 -h photoperiod. Individual plants were transplanted into $12.7-\mathrm{cm}$ pots of autoclaved Wooster silt-loam soil after the vernalization period. Pots were placed on greenhouse benches in a completely randomized design and maintained at $20.8 \pm 2.8^{\circ} \mathrm{C}$ with a 12-h photoperiod of supplemental lighting (10). Fertilization was in the form of slow-release pellets (triple 14 Osmocoat; Scotts, Inc., Marysville, OH) applied when the plants were potted, and weekly watering with liquid fertilizer (triple 20 Peter's fertilizer solution; Scotts, Inc.; 10). Insect pests and foliar diseases were controlled using standard labeled chemicals to obtain healthy wheat plants for inoculation (10). Fungicides that are known to not control $F$. graminearum epidemics were used to control foliar diseases in the greenhouse.

Fungal isolates and inoculum preparation. Twenty $F$. graminearum isolates from infected wheat in Ohio were tested for aggressiveness based on inoculating the central floret of spikes of $\mathrm{cv}$. Norm, a susceptible spring wheat, with a macroconidial suspension in the greenhouse. Four isolates that caused $100 \%$ disease incidence and severity were used in inoculation tests (10). The isolates were stored frozen $\left(0^{\circ} \mathrm{C}\right)$ on dried colonized plugs of corn meal agar (Fisher Scientific, Inc., Fair Lawn, NJ). Individual isolates were cultured at room temperature on carrot agar (15) in petri dishes under a bank of ultraviolet (UV) and fluorescent lights in the lab (25). Petri dishes were positioned lid side up in a single layer. After 14 days, the surface of the medium was scraped with a rubber policeman to dislodge macroconidia. The mycelial mat was removed from the petri dish and placed on four layers of cheesecloth, then washed with $5 \mathrm{ml}$ of sterile water and strained to sequester macroconidia in suspension for inoculations.

The scraped petri dishes then were used to produce ascospores. Mycelium growing on the surface of the agar and along the vertical sides of the petri dish bottom was removed by scraping with a rubber policeman. Removal of mycelium enhanced the development of perithecia on the agar surface from mycelium within the agar. The lid of the petri dish was sprayed with $70 \%$ ethanol and wiped with sterile Kimwipes. Sterile, deionized (DI) water $(800 \mu \mathrm{l})$ was pipetted onto the agar and spread over the entire surface with a rubber policeman. The petri dishes then were placed lid side up under the light bank previously described.

Upon formation of perithecia, petri dishes were inverted. The length of time for formation of perithecia varied among isolates, but was consistent for each isolate. Each isolate produced perithecia covering the surface of the agar in 7 to 10 days after being scraped, and ascospores were produced 4 to 5 days later.

Ascospores were harvested every other day from petri dish lids. Lids from inverted petri dishes were removed in an laminar air hood and $500 \mu \mathrm{l}$ of sterile, DI water was added to each lid. A rubber policeman was scraped across the lid to dislodge ascosurface was scraped, the film of water was pooled in the tilted lid, micropipetted from the lid and placed in sterile glass vials. The petri dish lid then was sterilized by spraying with $70 \%$ ethanol and wiping with sterile Kimwipes. The dishes then were inverted and placed under the light banks. Several harvests of ascospores were obspores into the water. Once the entire lid

tained from a single petri dish culture through this procedure. Petri dishes were discarded when ascospore production decreased, approximately 1 week after the beginning of ascospore formation.

The concentration of macroconidia and ascospores in suspension for each isolate was determined using a hemacytometer and adjusted with sterile, DI water to $6 \times$ $10^{4}$ and $6 \times 10^{6}$ spores $/ \mathrm{ml}$, respectively. The suspensions of the four isolates then were combined to create the macroconidial or ascospore suspensions used to inoculate plants. Suspensions were prepared fresh daily, or 1-day-old suspensions were used that had been stored at $1{ }^{\circ} \mathrm{C}$.

Inoculation techniques and conditions. Four inoculation procedures were evaluated: (i) a macroconidial suspension injection into a central floret on the spike using a hypodermic syringe, (ii) spraying a macroconidial suspension onto the entire surface of the spike to the point of run-off with a hand atomizer, (iii) placing a drop of ascospore suspension on the junction of the glume, lemma, and palea of marked, emasculated spikelets along one side of the spike, and (iv) placing a drop of ascospore suspension on groups of anthers associated with marked spikelets along one side of the spike. Inoculation methods $i$ and ii were standard screening procedures. Inoculation method i has been used to evaluate resistance to spread of $F$. graminearum in the spike or type II resistance (3) and inoculation method ii has been used to evaluate resistance to primary infection or type I resistance (31). An injection of sterile water with a hypodermic syringe into a central floret was used as a control to differentiate damage caused by injury to the spikelet tissues from the syringe needle.

Inoculation methods iii and iv were developed to evaluate the resistance response of specific spike tissues. Micropipetting 1 $\mu \mathrm{l}$ of the ascospore suspension onto emasculated spikelets on one side of the spike was used to evaluate infection via the

Table 1. Mean disease severity and incidence of genotypes selected from the 1999 uniform winter wheat Fusarium head blight screening nursery

\begin{tabular}{|c|c|c|c|c|c|}
\hline \multirow[b]{2}{*}{ Genotype } & \multicolumn{3}{|c|}{ Nursery data ${ }^{a}$} & \multirow[b]{2}{*}{ Type $\mathbf{I}^{\mathbf{b}}$} & \multirow[b]{2}{*}{ Type II } \\
\hline & Incidence $(\%)$ & Severity $(\%)$ & DON (ppm) & & \\
\hline Ernie & 36.1 & 8.6 & 3.8 & PR & PR \\
\hline Goldfield & 38.1 & 14.1 & 3.9 & PR & $\mathrm{S}$ \\
\hline OH609 & 35.4 & 15.9 & 2.7 & PR & $\mathrm{S}$ \\
\hline OH552 & 53.9 & 11.8 & 4.7 & $\mathrm{~S}$ & PR \\
\hline IL94-1909 & 28.3 & 9.1 & 5.6 & PR & PR \\
\hline IL95-4162 & 34.5 & 17.6 & 3.2 & PR & $\mathrm{S}$ \\
\hline 2545 & 61.0 & 19.9 & 10.4 & $\mathrm{~S}$ & $\mathrm{~S}$ \\
\hline $\operatorname{LSD}(0.05)$ & 13.3 & 6.4 & 2.6 & $\ldots$ & $\ldots$ \\
\hline
\end{tabular}

${ }^{a}$ Nurseries were evaluated at six locations across the United States and one location in Ontario, Canada. Incidence is the mean percentage of spikes with at least one symptomatic spikelet. Severity is the mean percentage symptomatic spikelets per spike. DON $=$ deoxynivalenol concentration in parts per million (ppm).

${ }^{\mathrm{b}}$ Relative reaction compared to 2545 based on incidence (type I resistance) and severity (type II resistance) assessments, where $\mathrm{PR}=$ partially resistant and $\mathrm{S}=$ susceptible. Classification based on cultivar means from incidence or severity significantly different (for PR classification) or not significantly different (for S classification) from the susceptible cultivar 2545 for type I and type II resistance respectively, according to Fisher's protected least significant difference (LSD; $P \leq 0.05$ ). 
modified leaves of the floret. Emasculation was accomplished by removal of all anthers from each floret with fine tipped forceps. Care was taken to limit damage of the developing kernel or other floret structures. The inoculation drop was placed where the glume, lemma, and palea margins intersected. Drops of inoculum remained on the inoculation point unless the wheat spike was forcefully agitated. After a few minutes, the drops had flattened and adhered to the area of intersection. Inoculated spikelets were marked with a nontoxic permanent marker before inoculation and only spikelets on one side of each spike were inoculated.

Inoculation method iv involved micropipetting $1 \mu \mathrm{l}$ of ascospore suspension onto groups of anthers or on the spikelet surface adjacent to individual anthers. This technique was used to simulate infection via anthers. Inoculation of individual anthers was not feasible because the 1- $\mu$ d drop was larger than an individual anther. Spikelets with inoculated anthers were marked with a nontoxic permanent marker before inoculation. Only anthers from spikelets on one side of each spike were inoculated.

As indicated, two different inoculum types, macroconidia or ascospores, were used in inoculation techniques. Macroconidial suspensions were used with the central floret injection method and atomizing the surface of the spike method because these techniques have been used in previous studies $(3,4,31)$. Ascospore suspensions were used when inoculating glumes of emasculated spikelets and inoculating anthers to simulate the type of inocu-

All inoculation treatments were applied when $50 \%$ of the florets on the spike had extruded anthers. When possible, the spike of the main tiller was inoculated; however, if this spike was considered inadequate, a spike on one of the secondary tillers was used. One spike from the individual plant per pot was considered one replication. For each inoculation treatment, there were 20 lum most likely to cause natural infections on these tissues $(3,26,27)$.

replications per genotype per block. A block was considered an experimental repeat. Three blocks were separated over 3 months and three greenhouses.

Plants were inoculated and immediately placed in a mist chamber in a separate room from the greenhouse. The mist chamber was a skeleton of $2.54-\mathrm{cm}$ diameter PVC pipe measuring 2.3 by 1.4 by 1.0 $\mathrm{m}$ and enclosed by polyethylene sheeting with adjustable sides. An air atomizer with a fluid nozzle $\left(0.56 \mathrm{~kg} / \mathrm{cm}^{3}\right.$ of water; \#2850 SS; Spraying Systems, Co., Spokane, WA) and an air nozzle $\left(4.2 \mathrm{~kg} / \mathrm{cm}^{3}\right.$ air; \#70) misted $30 \mathrm{ml}$ of water for $30 \mathrm{~s}$ every $3 \mathrm{~min}$ above a polyethylene canopy over the plants. This canopy, between the plants and the spray nozzles, ensured a fine mist surrounding the plants and prevented accumulation of water on the inoculation site. The temperature in the mist chamber was approximately $22^{\circ} \mathrm{C}$ and the relative humidity was approximately $100 \%$. Inoculated plants were incubated in the mist chamber for $48 \mathrm{~h}$ before being returned to the greenhouse.

Inoculated plants were returned to the same greenhouse in which they had been grown. Care was taken to separate noninoculated plants from inoculated plants on benches to prevent contamination. Inoculated plants were again arranged in a random design on the benches.

Disease assessments and data analysis. Spikes inoculated using each of the four methods were visually rated for disease severity 7,10 , and 14 days after inoculation (DAI) using a visual scale where severity was the percentage of symptomatic spikelets per spike (34). In addition, plants inoculated by the standard central floret injection (method i) and micropipetting ascospore suspensions onto anthers and glumes on one side of the spike (methods iii and iv) were scored for the percentage of spikelets that developed symptoms of those that were inoculated. This assessment method was not used when the entire spike surface was atomized with a conidial suspension because the percentage of

Table 2. Mean Fusarium head blight severity (mean percentage of symptomatic spikelets per spike) 14 days after inoculation (DAI) for seven wheat genotypes using four different inoculation techniques

\begin{tabular}{lccccc}
\hline & \multicolumn{4}{c}{ Inoculation technique $^{\mathbf{a}}$} & \\
\cline { 2 - 4 } Genotype & $\begin{array}{c}\text { Floret } \\
\text { injection }\end{array}$ & $\begin{array}{c}\text { Spike } \\
\text { atomized }\end{array}$ & $\begin{array}{c}\text { Ascospores } \\
\text { on glumes }\end{array}$ & $\begin{array}{c}\text { Ascospores } \\
\text { on anthers }\end{array}$ & $\begin{array}{c}\text { Genotype } \\
\text { mean }\end{array}$ \\
\hline Ernie & 11.1 & 41.8 & 4.4 & 30.0 & 21.8 \\
Goldfield & 8.5 & 31.3 & 3.9 & 17.1 & 23.9 \\
OH609 & 16.6 & 27.2 & 15.1 & 36.5 & 23.9 \\
OH552 & 15.3 & 47.4 & 15.0 & 30.2 & 23.9 \\
IL94-1909 & 9.5 & 28.8 & 8.8 & 17.6 & 16.2 \\
IL95-4162 & 9.2 & 36.5 & 8.7 & 35.8 & 22.6 \\
2545 & 14.3 & 38.8 & 8.1 & 28.0 & 22.3 \\
Inoculation technique mean & 12.1 & 36.0 & 9.2 & 27.8 & 22.1 \\
LSD (0.05) & NS & 11.1 & 6.4 & 9.8 & $\ldots$ \\
\hline
\end{tabular}

a Each inoculation treatment had 20 replicates per genotype in three blocks separated in time.

${ }^{b}$ Mean comparison based on separate analyses of variance for main effect of inoculation technique according to Fisher's protected least significant difference (LSD; $P \leq 0.05$ ); NS = no significant difference $(P \leq 0.05)$. symptomatic spikelets could be affected by infection of the rachis or adjacent infected spikelets, not just symptoms resulting from inoculation of the spikelet being assessed.

The AUDPC was estimated based on the average of each interval between two disease assessment dates multiplied by the actual time in days between the two assessment dates, and standardized by dividing the total number of days the disease assessments were recorded (5). Analysis of variance (ANOVA) was conducted using the general linear model in MINITAB (release 12; MINITAB, Inc., State College, PA) for the mean disease assessments for each inoculation technique. Pearson's correlations for the relationship between field disease assessments and disease assessments for each of the four greenhouse inoculation methods were calculated in MINITAB. Correlations were calculated based on the mean of seven field trial locations and mean values for inoculation method combined over genotype from greenhouse experiments.

\section{RESULTS}

The control inoculation, an injection of sterile water into a single central floret, caused no disease symptoms or only negligible symptoms on a few spikes. Values from the controls were excluded from the data analysis because inclusion would have made the error mean square artificially low. ANOVA indicated a significant effect of genotype-inoculation technique interaction for disease severity $(P=0.002)$ and AUDPC based on disease severity $(P<$ 0.001). Additionally, there was a significant interaction effect of genotypeinoculation technique for percentage of inoculated spikelets per spike with disease symptoms $(P<0.001)$ and AUDPC based on the percentage of inoculated spikelets per spike with disease symptoms $(P=$ $0.005)$. These interactions indicated that the genotypes responded differently to the different inoculation techniques as well as the assessment methods used to evaluate the genotype reactions.

Inoculation effect on disease severity. To understand the effect of inoculation technique on reaction of the genotypes, ANOVA was conducted for each inoculation technique separately. Overall, higher disease severities were obtained by atomizing the entire spike or by placing ascospores on anthers than severities obtained by the central floret injection technique or by placing ascospores on glumes (Table 2). ANOVA for disease severity indicated that inoculating by placing ascospores on glumes and the central floret injection did not differentiate any of the genotypes from the susceptible cv. 2545 (Table 2). However, disease was significantly less severe on OH609 than on 2545 when inoculated by atomizing conidia onto the surface of the spike. Only IL94-1909 and Goldfield had statistically lower disease severity 
ratings than the susceptible control when inoculated by placing ascospores on the anthers.

AUDPC based on disease severity was significantly lower for Goldfield than for 2545 when inoculated by placing ascospores on anthers, but not when the other inoculation techniques were used (Table 3). Atomizing conidia onto the spike resulted in a significantly lower disease severity AUDPC for OH609 than for 2545. The central floret injection and placing ascospores on glumes did not differentiate among the seven genotypes tested based on severity AUDPC.

Similar results were obtained in identifying genotypes with resistance responses using a single severity assessment 14 DAI (Table 2) and AUDPC based on severity assessments 7, 10, and 14 DAI (Table 3). Either assessment method identified OH609 as resistant when the spike was atomized with conidia and Goldfield was identified as resistant by both assessment methods when inoculated by placing ascospores on anthers. Although IL95-4162 had a significantly lower severity than 2545 based on severity assessment 14 DAI when inoculated by placing ascospores on anthers, this difference was not significant when AUDPC was used to assess the resistance reaction.

Inoculation effect on percentage of inoculated spikelets with symptoms. In general, the central floret injection technique causes the highest percentage of inoculated spikelets to become diseased (mean $=83.5 \%)$, followed by placing ascospores on groups of anthers (mean = $61.3 \%$ ) (Table 4). Placing ascospores on the intersection of the glumes, lemmas, and paleas caused the lowest percentage of inoculated spikelets to become diseased $($ mean $=26.5 \%)$. The percentage of inoculated spikelets developing symptoms 14 DAI was lower for Ernie than for 2545 when plants were inoculated by placing ascospores on glumes, and there were no differences among genotypes when inoculated by the central floret injection technique or by placing ascospores on anthers.

Similar results were obtained when ANOVA was conducted for AUDPC based on the percentage of inoculated spikelets developing disease symptoms. Only Ernie and IL95-4162 had a lower AUDPC value than 2545 when ascospores were placed on glumes (Table 5). No genotypes were differentiated from each other when inoculated using the central floret injection technique or ascospore placement on anthers.

Correlations. Most correlations between Fusarium head blight assessments taken in the field and disease assessments used to evaluate disease reactions in the greenhouse were low and all were not significant at $P \leq 0.05$ (Table 6). The higher correlation coefficients generally were associated with the relationship between field disease incidence and disease assessments when spikes were inoculated by injecting the central floret or by placing ascospores on glumes. Only two inoculation techniques, central floret inoculation $(r=0.61)$ and atomizing spike surfaces with conidia $(r=0.63)$, were correlated with field incidence based on a significance level of $P \leq 0.15$.

Table 3. Mean area under the disease progress curve for Fusarium head blight severity (mean percentage of symptomatic spikelets per spike) for seven wheat genotypes inoculated using four different inoculation techniques

\begin{tabular}{lccccc}
\hline & \multicolumn{3}{c}{ Inoculation technique } & \\
\cline { 2 - 5 } Genotype & $\begin{array}{c}\text { Floret } \\
\text { injection }\end{array}$ & $\begin{array}{c}\text { Spike } \\
\text { atomized }\end{array}$ & $\begin{array}{c}\text { Ascospores } \\
\text { on glumes }\end{array}$ & $\begin{array}{c}\text { Ascospores } \\
\text { on anthers }\end{array}$ & $\begin{array}{c}\text { Genotype } \\
\text { mean }\end{array}$ \\
\hline Ernie & 7.7 & 33.7 & 3.2 & 23.5 & 17.0 \\
Goldfield & 7.3 & 25.6 & 2.5 & 12.8 & 12.1 \\
OH609 & 11.6 & 19.7 & 9.6 & 26.0 & 16.6 \\
OH552 & 9.6 & 36.3 & 10.7 & 23.8 & 20.1 \\
IL94-1909 & 6.4 & 22.5 & 6.6 & 14.1 & 12.4 \\
IL95-4162 & 6.9 & 28.3 & 6.5 & 27.9 & 17.4 \\
2545 & 9.3 & 30.6 & 5.1 & 21.1 & 16.5 \\
Inoculation technique mean & 8.4 & 28.1 & 6.3 & 21.3 & 16.0 \\
LSD (0.05) & NS & 9.8 & 4.2 & 7.8 & $\ldots$ \\
\hline
\end{tabular}

${ }^{a}$ Each inoculation treatment had 20 replicates per genotype in three blocks separated in time.

${ }^{\mathrm{b}}$ Mean comparison based on separate analyses of variance for main effect of inoculation technique according to Fisher's protected least significant difference (LSD; $P \leq 0.05$ ); NS = no significant difference $(P \leq 0.05)$.

Table 4. Percentage of inoculated spikelets per spike with symptoms of Fusarium head blight 14 days after inoculation for seven wheat genotypes using three different inoculation techniques

\begin{tabular}{lcccc}
\hline & \multicolumn{3}{c}{ Inoculation technique $^{\mathbf{a}}$} & \\
\cline { 2 - 4 } Genotype & $\begin{array}{c}\text { Floret } \\
\text { injection }\end{array}$ & $\begin{array}{c}\text { Ascospores on } \\
\text { glumes }\end{array}$ & $\begin{array}{c}\text { Ascospores on } \\
\text { anthers }\end{array}$ & $\begin{array}{c}\text { Genotype } \\
\text { mean }\end{array}$ \\
\hline Ernie & 79.0 & 15.5 & 62.8 & 52.4 \\
Goldfield & 90.0 & 27.0 & 59.6 & 58.9 \\
OH609 & 77.4 & 33.4 & 64.3 & 58.4 \\
OH552 & 81.3 & 37.7 & 61.1 & 60.0 \\
IL94-1909 & 84.8 & 21.2 & 54.1 & 53.4 \\
IL95-4162 & 82.3 & 21.9 & 66.2 & 56.8 \\
2545 & 90.2 & 28.6 & 60.6 & 59.8 \\
Inoculation technique mean & 83.5 & 26.5 & 61.3 & 57.1 \\
LSD $(0.05)^{\mathrm{b}}$ & $\mathrm{NS}$ & 10.2 & $\mathrm{NS}$ & $\ldots$ \\
\hline
\end{tabular}

${ }^{a}$ Each inoculation treatment had 20 replicates per genotype in three blocks separated in time.

${ }^{\mathrm{b}}$ Mean comparison based on separate analyses of variance for main effect of inoculation technique according to Fisher's protected least significant difference (LSD; $P \leq 0.05$ ); NS = no significant difference $(P \leq 0.05)$.

Table 5. Mean area under the disease progress curve based on percentage of inoculated spikelets developing Fusarium head blight symptoms for seven wheat genotypes inoculated using three different inoculation techniques

\begin{tabular}{lcccc}
\hline & \multicolumn{3}{c}{ Inoculation technique $^{\mathbf{a}}$} & \\
\cline { 2 - 4 } Genotype & $\begin{array}{c}\text { Floret } \\
\text { injection }\end{array}$ & $\begin{array}{c}\text { Ascospores on } \\
\text { glumes }\end{array}$ & $\begin{array}{c}\text { Ascospores on } \\
\text { anthers }\end{array}$ & $\begin{array}{c}\text { Genotype } \\
\text { mean }\end{array}$ \\
\hline Ernie & 76.1 & 10.0 & 58.1 & 48.1 \\
Goldfield & 83.8 & 18.4 & 54.3 & 52.2 \\
OH609 & 74.8 & 23.4 & 54.9 & 51.0 \\
OH552 & 74.4 & 29.6 & 52.9 & 52.3 \\
IL94-1909 & 81.8 & 16.3 & 48.4 & 48.8 \\
IL95-4162 & 75.0 & 12.8 & 62.3 & 50.0 \\
2545 & 87.2 & 20.8 & 54.9 & 54.3 \\
Inoculation technique mean & 79.0 & 18.8 & 55.1 & 51.0 \\
LSD $(0.05)^{\mathrm{b}}$ & NS & 7.9 & NS & $\ldots$ \\
\hline
\end{tabular}

${ }^{\text {a }}$ Each inoculation treatment had 20 replicates per genotype in three blocks separated in time.

${ }^{\mathrm{b}}$ Mean comparison based on separate analyses of variance for main effect of inoculation technique according to Fisher's protected least significant difference (LSD; $P \leq 0.05$ ); NS $=$ no significant difference $(P \leq 0.05)$. 
using two inoculation techniques to evaluate resistance to $F$. graminearum in the greenhouse. These are atomizing macroconidial suspensions on the entire spike to evaluate resistance to primary infection (type I resistance) and injecting a central floret of the spike with a macroconidial suspension to evaluate spread of the pathogen within the spike (type II resistance). Our results with greenhouse inoculation tests indicated that the reaction of genotypes to $F$. graminearum varied with the procedures used to inoculated spike tissues. However, only one to two of the six genotypes that had significantly lower disease severity or incidence in the field had significantly lower disease assessments than the susceptible cultivar when evaluated in the greenhouse using several different inoculation procedures. Additionally, the two standard inoculation procedures did not detect the resistances in the cultivars as expected from field tests. These results undoubtedly question the reliability of these procedures to adequately evaluate the types of resistances expressed by moderately resistant genotypes in the field.

Atomizing macroconidia onto the surface of the spike has been used as a method to evaluate resistance to fungal penetration of the spike tissues and has been assessed as the proportion of individual spikelets affected per spike $(18,31)$. In contrast, to estimate type I resistance in the field, disease incidence values have been calculated as the proportion of symptomatic spikes of the total number of spikes sampled $(3,31)$. No detailed studies have demonstrated that field incidence and atomizing spikes with conidia in the greenhouse effectively assesses resistance to infection. In both situations, all spike structures, including anthers, glumes, lemmas, paleas, and the rachis, have equal opportunity to be inoculated. There appears to be no way of dif- ferentiating between the response conditioned by type I or type II resistance after atomizing the spike with conidial suspensions. It is possible that resistance in each of the inoculated floral structures could be controlled by different genetic mechanisms. Type I resistance has been thought to be mediated by passive and active resistance mechanisms (1,31). Passive mechanisms generally are described as resulting from disease escape, due to characteristics such as cultivar maturity (timing of anthesis), plant height, floral structure (upright spikes, absence of awns), and the shedding of extruded anthers $(10,30,31)$. However, the procedures used in the greenhouse generally are designed to bypass any passive resistance mechanisms.

In an attempt to evaluate type I resistance, two new inoculation techniques were tested: placing ascospores on groups of anthers and placing ascospores on the intersection of the glume, lemma, and palea of emasculated spikelets. These inoculation techniques resulted in infected spikelets with mean percentage of inoculated spikelets per spike being higher when ascospores were placed on anthers (mean $61.3 \%$ across genotypes) than when ascospores were placed on glumes of emasculated spikelets (mean $26.6 \%$ across genotypes) (Table 4). However, the percentage of inoculated spikelets per spike with symptoms of any genotype tested was no different from the susceptible cv. 2545 when ascospores were placed on anthers; when ascospores were placed on glumes, only the cv. Ernie had statistically less symptomatic inoculated spikelets than the susceptible control. This may indicate that Ernie was the only genotype that had sufficient type I resistance to be detected by these methods. Additionally, in the genotypes tested, anthers apparently had little resistance to infection, whereas glume

Table 6. Pearson's correlation coefficients $(r)$ among 1999 Fusarium head blight field nursery mean disease assessments and mean disease assessments for four greenhouse inoculation techniques

\begin{tabular}{|c|c|c|c|c|}
\hline Greenhouse assessments $^{a}$ & $\begin{array}{l}\text { Central floret } \\
\text { injection }\end{array}$ & $\begin{array}{c}\text { Spike } \\
\text { atomized }\end{array}$ & $\begin{array}{l}\text { Ascospores } \\
\text { on glumes }\end{array}$ & $\begin{array}{l}\text { Ascospores } \\
\text { on anthers }\end{array}$ \\
\hline \multicolumn{5}{|l|}{ Severity 14 DAI } \\
\hline Field severity & 0.26 & -0.11 & 0.15 & 0.39 \\
\hline Field incidence & 0.55 & $0.63^{\mathrm{b}}$ & 0.21 & 0.15 \\
\hline \multicolumn{5}{|l|}{ Severity AUDPC } \\
\hline Field severity & 0.40 & -0.22 & 0.09 & 0.36 \\
\hline Field incidence & $0.61^{\mathrm{b}}$ & 0.57 & 0.58 & 0.20 \\
\hline \multicolumn{5}{|c|}{ Inoculated spikelets with symptoms } \\
\hline Field severity & 0.37 & $\ldots$ & 0.36 & 0.47 \\
\hline Field incidence & 0.38 & $\ldots$ & 0.55 & 0.09 \\
\hline \multicolumn{5}{|l|}{ AUDPC (\%) } \\
\hline Field severity & 0.29 & $\ldots$ & 0.21 & 0.42 \\
\hline Field incidence & 0.32 & $\ldots$ & 0.58 & -0.02 \\
\hline
\end{tabular}

${ }^{a}$ Greenhouse assessments included severity as the mean percentage of symptomatic spikelets per spike and the percentage of inoculated spikelets developing symptoms. DAI = days after inoculation and AUDPC = area under the disease progress curve where assessments were recorded 7, 10, and 14 DAI. Each inoculation treatment had 20 replicates per genotype (seven genotypes). Field severity was the mean percentage of symptomatic spikelets per spike and incidence was the mean percentage spikelets with at least one symptomatic spikelet.

b Significant where $P \leq 0.15$. tissues may harbor some type of resistance that limits infection. These flower structures could limit ingress of the fungus compared with colonization of the floret by way of exposed anthers. This is in agreement with the findings of Pritsch et al. (28), where Sumai 3 (resistant) and Wheaton (susceptible) cultivars had no major differences in the timing or development of the infection process in floret structures within $76 \mathrm{~h}$ after atomizing spikes with macroconidia, assuming that the inoculation procedure deposited macroconidia on anthers as well as glumes and the fungus entered the florets by way of anthers.

Disease severity, evaluated in the field or greenhouse by visually estimating the percentage of symptomatic spikelets per spike, has been used to evaluate resistance to spread of $F$. graminearum in the spike, and is used as an indicator of type II resistance $(3,31)$. The central floret injection procedure is considered the standard test to evaluate pathogen spread within the spike or type II resistance in the greenhouse $(3,18)$. This technique places a conidial suspension inside the floret, thereby eliminating the dependency of hyphal penetration of exposed floret tissues for infection. Genotypes that limit colonization of adjacent noninoculated spikelets are considered resistant. The central floret injection technique did not detect differences in genotype responses in this study (Tables 2-5). These results indicate that type II resistance was not detectable in the genotypes tested or that the level of type II resistance present in the genotypes was not great enough to be differentiated by the testing procedure. However, disease severity ratings from the field indicated that three of the six genotypes had some level of type II resistance (Table 1). Because type II resistance is considered to be more stable and least affected by the environment $(3,4)$, we have reservations about the ability of this greenhouse technique to quantitatively detect resistance to spread of the pathogen in spike tissues.

Type II resistance is thought to be mediated by active mechanisms that hinder the growth of the pathogen from the point of inoculation through the various tissues of the spike (29). Some of the resistance mechanisms are appositional deposits of various plant materials around the hyphae (papillae) and accumulation of hypersensitive response and pathogenicity-related proteins $(28,29)$. Perhaps some of these resistance mechanisms are not well expressed under certain environmental conditions in greenhouses, especially in genotypes that have only moderate levels of partial resistance. Artificial inoculation techniques have been used successfully in detecting differences in genotypes with high levels of partial resistance, such as resistant germ plasm sources $(18,26,31)$. It appears that resistance to $F$. graminearum in wheat spike tissues is complicated and 
may require additional methodology to identify specific resistance reactions in genotypes with moderate levels of partial resistance.

We feel that the central floret injection method is adequate for detecting high levels of type II resistance; however, inoculating spikes by atomizing macroconidia on the surface of all spike tissues cannot be used to differentiate between type I and type II resistance. Additionally, inoculating extruded anthers with ascospores was nearly as efficient in causing high levels of disease on inoculated spikelets as the central floret injection technique (Table 4), indicating that anthers probably contribute little to any resistance mechanism. This is probably the reason that epidemics of Fusarium head blight occur when favorable weather conditions coincide with anthesis (1$3,8,19,21,22,26,27)$. Last, using a single disease assessment 14 DAI appeared to be just as effective in evaluating the reaction to $F$. graminearum in the greenhouse as AUDPC based on assessments 7, 10, and 14 DAI.

\section{ACKNOWLEDGMENTS}

We thank A. L. Johnston, S. Chapman, E. Chanay, and L. D. Herald for technical assistance; and E. D. DeWolf for his contributions and critiques.

\section{LITERATURE CITED}

1. Andersen, A. L. 1948. The development of Gibberella zeae head blight of wheat. Phytopathology 38:595-611.

2. Arseniuk, E., Foremska, E., Goral, T., and Chelkowski, J. 1999. Fusarium head blight reactions and accumulation of deoxynivalenol (DON) and some of its derivatives in kernels of wheat, triticale, and rye. J. Phytopathol. 147:577-590.

3. Bai G.-H., and Shaner, G. 1994. Scab of wheat: prospects for control. Plant Dis. 78:760-766.

4. Bai, G.-H., and Shaner, G. 1996. Variation in Fusarium graminearum and cultivar resistance to wheat scab. Plant Dis. 80:975-979.

5. Campbell, C. L., and Madden, L. V. 1990. Introduction to Plant Disease Epidemiology. John Wiley \& Sons, New York.

6. Campbell, K. G., and Franchino, B. 1999. Uniform winter wheat Fusarium head blight screening nursery 1999 nursery report. Ohio State Univ. Hortic. Crop Sci. Ser. 690

7. Campbell, K. A. G., and Lipps, P. E. 1998. Allocation of resources: Sources of variation in Fusarium head blight screening nurseries. Phytopathology 88:1078-1086.

8. DeWolfe, E. D., Madden, L. V., and Lipps, P. E. 2003. Risk assessment models for wheat Fusarium head blight epidemics based on with-in season weather data. Phytopathology 93:428-435.

9. Dill-Macky, R., and Jones, R. K. 2000. The effect of previous crop residues and tillage on Fusarium head blight of wheat. Plant Dis. 84:71-76.

10. Engle, J. S. 2002. Evaluation and characterization of resistance to Fusarium head blight in winter wheat. M.Sc. thesis, The Ohio State University, Columbus.

11. Fernandez, M. R. 1991. Recovery of Cochliobolus sativus and Fusarium graminearum from living and dead wheat and nongramineous winter crops in southern Brazil. Can. J. Bot. 69:1900-1906.

12. Fernando, W. G. D., Paulitz, T. C., Seaman, W. L., Dutilleul, P., and Miller, J. D. 1997. Head blight gradients caused by Gibberella zeae from area sources of inoculum in wheat field plots. Phytopathology 87:414-421.

13. Geiger, H. H., and Heun, M. 1989. Genetics of quantitative resistance to fungal diseases. Annu. Rev. Phytopathol. 27:317-341.

14. Jiang, G., Wu, Z., and Huang, D. 1994. Effects of recurrent selection for resistance to scab (Gibberella zeae) in wheat. Euphytica 72:107-113.

15. Klittich, C. J. R., and Leslie, J. F. 1988. Nitrate reduction mutants of Fusarium moniliforme (Gibberella fujikuroi). Genetics 118:417-423.

16. Lipps, P. E., and Engle, J. S. 2000. 2000 northern uniform winter wheat scab nursery report. Ohio State Univ. Plant Pathol. Dep. Ser. 110.

17. Martin, R. A., MacLeod, J. A., and Caldwell, C. 1991. Influences of production inputs on incidence of infection by Fusarium species on cereal seed. Plant Dis. 75:784-788.

18. McKendry, A. L., Bestgen, K. S., and O'Day, M. 2001. Types I and II resistance to Fusarium head blight in Asian and Italian germplasm. In: Proc. 2001 Natl. Fusarium Head Blight Forum.

19. McMullen, M., Jones, R., and Gallenberg, D. 1997. Scab of wheat and barely: a re-emerging disease of devastating impact. Plant Dis. 81:1340-1348.

20. Mesterhazy, A. 1995. Types and components of resistance to Fusarium head blight of wheat. Plant Breed. 114:377-386.

21. Mills, J. T. 1982. Development of fusaria and fusariotoxins on cereal grains in storage. Can. J. Plant Pathol. 4:217-218.

22. Milus, E. A., and Parsons, C. E. 1994. Evaluation of foliar fungicides for controlling Fusarium head blight of wheat. Plant Dis. 78:697699.

23. Murphy, P., and Navarro, R. 2001. Uniform southern soft red winter wheat Fusarium head blight screening nursery: 2001 nursery report. N.C. State Univ. Dep. Crop Sci., Raleigh, NC.

24. Murphy, P., Navarro, R., and Srnic, G. 2000 Uniform southern soft red winter wheat Fusarium head blight screening nursery: 2000 nursery report. N.C. State Univ. Dep. Crop Sci., Raleigh, NC.

25. Nelson, P. E., Toussoun, T. A., and Marasas, W. F. O. 1983. Fusarium Species: An Illustrated Manual for Identification. Pennsylvania State University, University Park.

26. Parry, D. W., Jenkinson P., and Mcleod L. 1995. Fusarium ear blight (scab) in small grain cereals-a review. Plant Pathol. 44:207 238.

27. Paulitz, T. C. 1996. Diurnal release of ascospores by Gibberella zeae in inoculated wheat plots. Plant Dis. 80:674-678.

28. Pritsch, C., Muehlbauer, G. J., Bushnell, W. R., Somers, D. A., and Vance, C. P. 2000. Fungal development and induction of defense response genes during early infection of wheat spikes by Fusarium graminearum. Mol. Plant-Microbe Interact. 13:159-169.

29. Ribichich, K. F., Lopez, S. E., and Vegetti, A. C. 2000. Histopathological spikelet changes produced by Fusarium graminearum in susceptible and resistant wheat cultivars. Plant Dis. 84:794-802.

30. Schlosser, E. 1997. Preformed structural and chemical barriers. Pages 84-99 in: Resistance of Crop Plants Against Fungi. H. Hartleb, R. Heitefuss, and H.-H. Hoppe, eds. Gustav Fischer, Jena, Germany.

31. Schroeder, H. W., and Christensen, J. J. 1963. Factors affecting resistance of wheat to scab caused by Gibberella zeae. Phytopathology 53:831-838.

32. Sneller, C. H., Lipps, P. E., and Herald, L. 2001. Northern uniform winter wheat scab nursery: report on 2000-2001 nursery. Ohio State Univ. Hortic. Crop Sci. Ser. 690.

33. Snijders, C. H. A. 1990. Genetic variation for resistance to Fusarium head blight in bread wheat. Euphytica 50:171-179.

34. Stack, R. W., and McMullen, M. P. 1995. A visual scale to estimate severity of Fusarium head blight in wheat. N. D. State Univ. Ext. Publ. PP-1095.

35. Wan, Y.-F., Yen, C., and Yang, J.-L. 1997. The diversity of head-scab resistance in Triticeae and their relation to ecological conditions. Euphytica 97:277-281. 